\title{
Monitoring And Device Electrical Control Equipment Based on Arduino Mega
}

\author{
Yunus Tjandi ${ }^{1)}$, H. Muddassir ${ }^{2)}$ \\ ${ }^{1}$ Electric Engineering, Technical Of Engineering University State Of Makassar, \\ ${ }^{2}$ Electric Engineering, Technical Of Engineering University State Of Makassar,
}

\begin{abstract}
The carelessness on the installation and control of the electrical equipment will cause many harms and accidents. Fire is one of the consequences of improper control on a home / building storey. this research aims to ; 1) generate prototype software-based on the control system arduino mega function to control and monitor the electrical equipment (reservoirs, electric lights, $K K B, K K K$, fan, air conditioning, and MCB), a home / building storey by using a smartphone. 2) To produce mega arduino based on the control tool that is used to control and monitor the electrical equipment on the software that has been made. 3) To build interfaces and applications based on the control system arduino mega, using a smartphone to control and monitor the electrical equipment of the home / multi-storey buildings, so it is safe from the danger of a short circuit. based on the design of electrical installations and design applications envisaged that the prototype controller is made to function properly. the results showed that the prototype tools made dapt controlling and monitoring all the electrical appliances of the home / multi-storey buildings, both of from close range and from a distance using a smartphone.
\end{abstract}

Keywords: device electrical equipment, prototype instrument control, arduino mega, smartphone, interface, reservoir.

\section{Introduction}

The electricity is used to support a variety of community activities. lighting of the lamp, the comfort of air conditioner, television and radio entertainment, ease of cooking, and many more benefits that we get from the mains. without electricity, a city will be completely dark and lose the beauty of the night, a mother hassles wash and process food and store a child difficulty sleeping because the air conditioner and the fan is not working. so great effect posed by electricity until we have been depended on it.

There have been many accidents and losses caused of the improper utilization of electricity. when the electrical installation in a home / building has been given voltage by PLN, the installation is no longer dominant in the category of personal, but it has become public domain. carelessness installation and use of electricity have fatal consequences. for example, a Home / burning building because of electrical short circuit could potentially propagate the fire to the surrounding buildings. this is certainly detrimental to people. There have been many news broadcast on television or the newspaper due to electrical fires, many of which even lead to death.

To prevent that required knowledge of the electrical installation is good and right. in Indonesia, electrical installation standards stated in general terms electrical installations (PUIL, 2000) ${ }^{[2]}$. This standard contains instructions on the implementation of electrical installations and terms.

The majority of human activities are currently very place on electricity, both primary and secondary nature. Electricity is also very important in personal, social, education and trade. can be imagined if the house / building long abandoned by their owners and forgot to extinguish the electrical equipment, home owners do not necessarily quiet and always anxious and restless. With the control system are made, homeowners / building does not need to worry, because the electrical equipment can be remotely controlled so as to minimize the incidence of fire or things that are not desirable.

Now a day, there have been many new technologies being created, one that will be made by the researchers is a mega arduino based controller that can monitor and control all the electrical equipment, including the security system from a distance, which is not widely known by the public. One uses the smartphone in this study is that it can be used for controlling electrical devices remotely. Based on the above background, eating in this study used a smartphone to control and monitor the entire system of the electrical equipment of a house / building storey.

The development of technology today has helped in improving the quality and welfare of human life. In line with these developments presented some technologies that can be applied in public life to helping human activity. Technology capable of controlling and monitoring the electrical safety system and device electrical equipment in the house / building storey and performance becomes necessary to improve the reliability, convenience and time efficiency for its users. 


\subsection{The Purpose Of The Research}

The general purposes of this research are to develop appropriate technology to create a mean of controlling and monitoring devices dapt electrical appliances to help consumers (power users) to regulate and control the electrical appliances at home, while the specific objectives of this study are.

1. Generate prototype software mega arduino-based control system that functions for control and monitoring devices electrical appliances, home / building storey by using a smartphone.

2. Produce mega arduino based control tool that is used to control and monitor the electrical equipment on the software that has been made.

3. Build interfaces and applications based control system arduino mega, using amartphone to control and monitor the electrical equipment of the home / building storey.

\subsection{The Urgency Of Research}

1. There are some things that are very urgency in this study, the first to be the cornerstone of urgency the need to do this research is the development of appropriate technologies needed by consumers of electricity users.

2. The second urgency is to reduce the use of electrical energy for the rooms that use electric lights that are not needed, it can be immediately extinguished through our smartphones.

3. The third urgency is able to turn on and extinguish (control and monitoring) all electric appliances inside a house or building storey.

4. The fourth urgency to extinguish the electrical safety devices found in the home / building storey, so it can secure from the dangers of electrical short circuit so as to avoid a fire hazard.

\section{Study Of Library And Relevant Research}

Development of technology today has helped in improving the quality and welfare of human life. in line with these developments presented some technologies that can be applied in public life to helping human activity. Technology capable of controlling and monitoring the electrical safety system and device electrical equipment in the house / building storey and performance becomes necessary to improve the reliability, convenience and time efficiency for its users.

\subsection{Near Field Communication (NFC) ${ }^{[1,3,6]}$}

With increasingly advanced of technology in data communication between devices, the benefits resulting from the NFC increasingly diverse, even some of them have started to be applied in various parts of the world. NFC menyerdehanakan data communication between devices that typically need to connect using bluetooth or wi-fi connection authentication and equations before you can use and it usually takes a long time, unlike the NFC authentication between devices is done only a few seconds.

NFC is a development of Bluetooth and RFID where the NFC are technologically that we use when communicating using blurtooth in the splicing process and RFID as a liaison wave anatr NFC device. NFC on smartphones have utility communications in moving the website, phone number, audia, videos, photos and phone contacts. Even between devices is done only a few seconds.

The advantages of NFC lies in its role as a technology that can unlock various forms of communication and transactions in a way that is very convenient when used by the user. NFC allows people to do things they want by touching or placing their device close to the desired service. it is the form of electronic services and interactions more easily accessible to many people. NFC works between two devices close together (usually at a distance of a few centimeters). After the connection is made in seconds, information can be exchanged between two devices using either NFC directly or through other wireless technologies, such as Bluetooth, Wi-Fi, USB or zigbee.The devices that have been using the NFC chip, such as smartphones would generate interactive services are easier and more convenient to use for consumers. Consumers will tend to adopt the most convenient way to access and pay barnag and services. NFC is only used pad aponsel, can turn your phone into a means of payment financial transaction as well as credit cards. Besides the consumer can feel comfortable in the deal, another advantage is that it can reduce the cost of paper such as ticketing fee or proof of payment.

\subsection{The Electrical Device Equipment}

The electrical equipment to be controlled and monitored in this study consisted of: a miniature circuit breaker (MCB), reservoir, electric lights, KKB, KKK, TV, refrigerator and fan. So all the electrical equipment that resides in a home / multi-storey building can be secured and controlled use of distance, where the located of the owners.

\subsection{Arduino Mega}

Arduino mega is an open source electronic kits designed specifically for enabling everyone to develop electronic devices that can interact with the kinds of sensors and controllers. Arduino Mega is a microcontroller 
board based ATMega 328. This board has a pin microcontroller input / digital output (six of which can be used as PWM outputs), 6 analog inputs, $16 \mathrm{nMHz}$ crystal oscillator, a USB connection, a power jack, ICSP head and the reset button, arduino mega able to support the microcontroller, can be connected to a computer via USB.

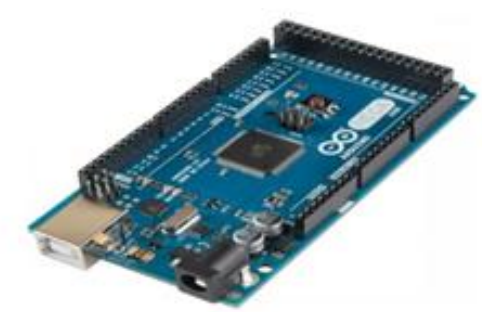

Figure 1. Arduino Mega ${ }^{[7,8]}$

Specification of arduino mega is:

a. Atmega Microcontroller 328

b. Operating At A Voltage Of $5 \mathrm{v}$

c. Input Voltage (Recommendation) 7-12 V

d. 6-20v Input Voltage Limits

e. Digital Pin Input / Output 14 (6 Supports Pwm)

f. Analog Input Pin 6

g. Current Per Pin Input / Output 40 Ma

h. Current For 3.3v Pin Is $50 \mathrm{Ma}$

i. Flash Memory $32 \mathrm{~Kb}$ (Atmega328) Of Which $2 \mathrm{~Kb}$ Used By Bootloader

j. $\quad$ Sram $2 \mathrm{~Kb}$ (Atmega 328)

k. $1 \mathrm{~Kb}$ Eeprom (Atmega 328)

1. A Clock Speed Of $16 \mathrm{Mhz}$

Arduino mega can be given start a USB connection or power supply, which the power selected automatically. Power supply can use a DC adapter or battery. The adapter can be connected by a striking jack adapter on supply input port connection. arduino mega board can be operated using external supply of 6-20 volts. If the supply is less than $7 \mathrm{~V}$, sometimes $5 \mathrm{~V}$ pin will supply less than five volts and the board may be unstable. If used more than $12 \mathrm{~V}$, the voltage regulator can be very hot and cause damage to the board.

\subsection{Ethernet Shield ${ }^{[4,6]}$}

Shiled is arduino ethernet module which enables arduino connected with the internet becoming a web server or communicate with other network devices using protol TCP / TP.

Specification of the ethernet shield is:
a. The Use Of Microchip Chip ENC28J60 SPI Ethernet Controller
b. Using The Standard RJ 45 Socket
c. Can Act As A Server Or Client

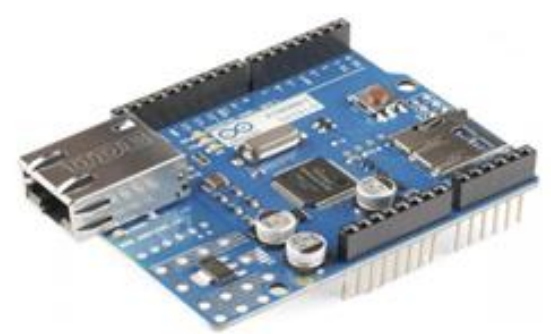

Figure 2. Ethernet Shield ${ }^{[6]}$

\subsection{Relay}

A relay is an electronic circuit that is simple and composed;
a. Switch
b. Electromagnetic Field (Coil Wire)
c. Iron Shaft

The components of working process are begun when the flow of electric current through the coil, and then create a magnetic field around it change the switch position so as to produce an electric current is greater. A simple component that is with minimal shape could generate larger currents. This simple component in its 
development uses as a basic component of a variety of electronic devices, light vehicles, electronic networks, television, radio and even in 1930 was used as the basic tools of computer whose existence is now being replaced by microprocessors such as Intel Corp and AMD. All of them because of the use of relay have advantages such as:

a. Can control their own current and voltage that is desired

b. Maximizes the magnitude of the voltage to reach the maximum limit.

Can use the switch as well as a coil is more than one, tailored to the needs.
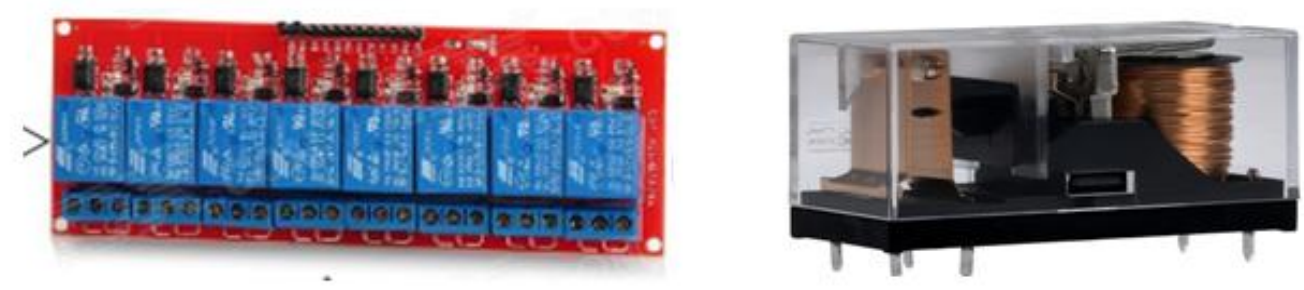

Figure 3. Relay ${ }^{[7]}$

Relay is also widely used to control machines that work sequentially prior to the microprocessor technology available, for example in injection molding machines, blow molding and the conveyor belt. The composition of the relay contacts are divided as follows.

a. NO (normally open), the relay will close when electrified

b. NC (normally closed), relay will open when electrified

c. $\mathrm{CO}$ (change over) relay has a contact center will disengage and unlock other contact-related. Relay has contacts who work according to the needs of NO and NC controlled device and controlled by a main contact is driven by the coil which can be a source of AC or DC. Relay outputs can control a high power circuits and low power in accordance with the functions assigned to him.

\subsection{Router}

A router is a computer networking hardware that is used to divide the protocol to other network members. The router function generally is a link between two or more networks to carry data from one network to another but different router with the switch, because the switch is only used to connect multiple computers and form a LAN (local area network). While routers are used to interconnect the LAN with other LAN.

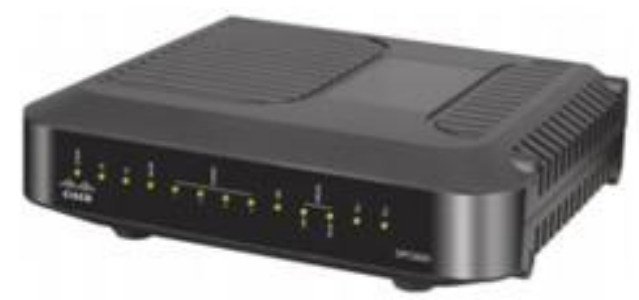

Figure 4. Modem Router

\subsection{The Relevant Of The Research}

1. Sean young Tjahyadi et al, 2012, in his article discusses android applications on mobile phones and the web with a feature setting $\mathrm{ON} / \mathrm{OFF} \mathrm{AC}$ and the AC temperature and displays the electrical energy consumption kwh meter wear.

2. Thesrumluk R. Et al, 2013, in the international journal discusses smart home management systems that use electrical energy claud computing (Shems). In his written discusses about the consumption of electrical power used by consumers and can be shut off electrical power to the consumers concerned through the Internet

3. RO seong Lee et al. In 2013, in his proceeding discusses about the smart home systems that utilize infrastructure web service by using a control system based on Android. This research results a system that utilizes the web service as a link between mobile devices based on Android with the microcontroller board.

\subsection{Types Of Research}

\section{Research Method} the control tool.

\section{This types}




\subsection{Materials And Equipment Of The Research}

\section{Materials}

a. board al.set

b. exchange switch 6 sets

c. KKK

d. electrical installation cable 1 set

e. lighting 6 pcs

f. reservoar

g. ethernet shield

h. digital ammeters

i. jack connector 1 set

j. jumper wire

k. adaptor

1. Fan

Equipment

a. computer, 1 set

b. TV

c. Access point TP-Link MR-3020 m. relay set

$\mathrm{n}$ KKB

o. MCB

p. Lighting panel (LP) set

q. Smartphone

r. Arduino mega

s. Boxes arduino

t. digital multimeter

u. USB cable

v. screw shield

w. Tool set

\subsection{Design Of Electrical Installations}

Thedesign of electrical installations are used that based on; regulations PUIL, 2000 SPLN, and LMK prevailing in Indonesia. In this desain is used safety MCB 2A, which serves to secure the entire device installation of electrical equipment in the building / home manually by using the switch trigger (press). each $\mathrm{KKB}, \mathrm{KKK}$, lights and MCB are used within the building must be controlled by arduino smart relay contained in the control panel. to control engine water pump to the reservoir, used water control sensors, which can be controlled directly from the arduino mega, via a relay board inside the panel. so if the water in the tank runs out of control (the lowest level), the pump will run automatically, and vice versa if the water in the tub is full control of the engine will stop (OFF) automatically. Electrical installation design drawings can be seen in Figure 5 and 6 below.

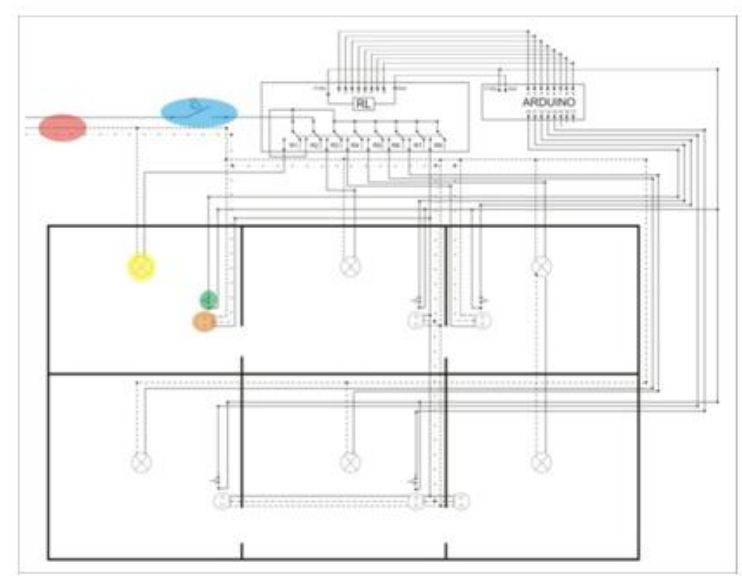

Figure 5. Wiring Diagram

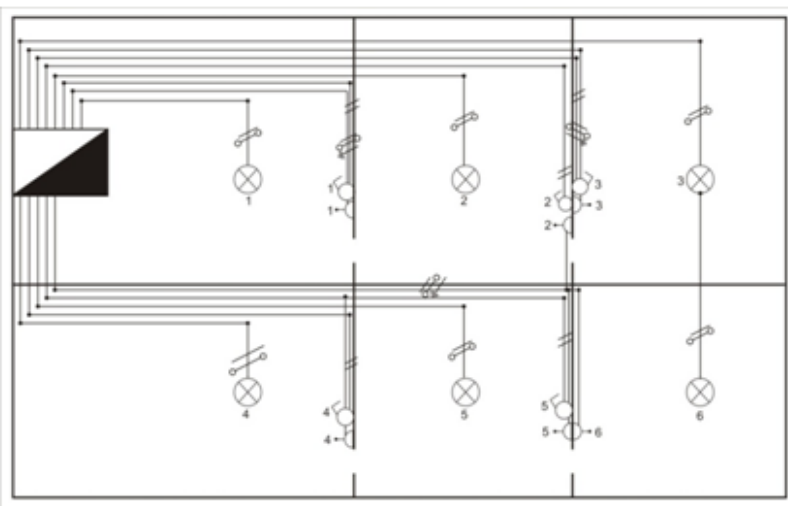

Figure 6. Installation Electric Diagram 


\subsection{The Data Collection Technique}

Data collection techniques used were interview techniques by expert electrical installation, library research, direct measurement techniques and documentation

\subsection{The Pilot Control System \\ 3.5.1 Local Network}

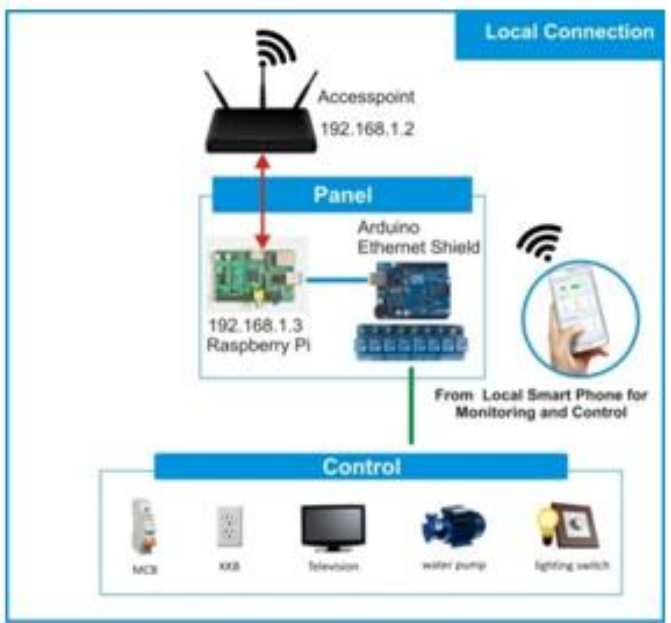

Figure 7. Arsitecture Local Network

In the picture above shows a accespoint used as a media liaison between the smartphone and rasberry that functions as a server and arduino mega serves as a tool for controlling and monitoring the electrical equipment (KKB, water pumps, lamp-electric lights, and $\mathrm{MCB}$ ). Smartphone serves as the controller to send instructions to the arduino mega via a web based on application that is contained in rasberry, with IP address 192.168.1.3. The workings of the control and monitoring tool is that on the instructions of the equipment arduino mega then forwarded to the relay device, which switches to the next, KKK, KKB, TV, reservoir, electric lights and MCB according to customer wishes.

\subsubsection{Internet Connection}

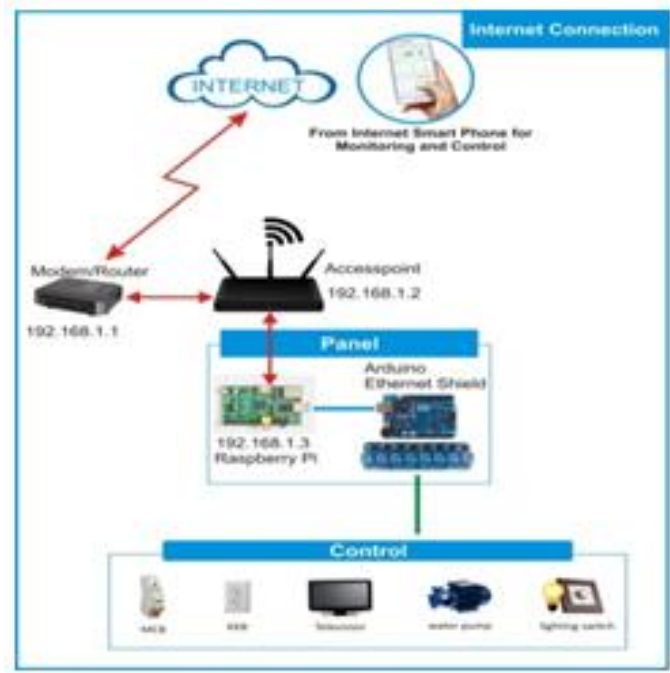

Figure 8. Arsitecture Internet Network

In the figure above is the development of local connections so that the user can control the electrical appliance (KKB, water pump machine, TV, electric lights and MCB) via an internet connection. in Figure 6 there and a modem / router those functions as a media liaison local and internet connection. so users can monitor and control the electric appliance the user must be able to access the address http://www.penelitiankendaligedung.ngrok.com on a user's smartphone, the next page will appear on the website amartphone used as a remote user to send instructions to arduino whose function is to control the electrical equipment in a building or house. 


\subsection{The Result Of The Research}

\section{Result And Discussion}

After the design of the application made by the research team, then made the design of electrical installations, such as in Figure 7 and Figure 8. Ssoftware has been enhanced further downloaded to arduino and ready to function. After testing of all devices of household electrical appliances, the obtained results as shown in Table 1 and 2.

Table 1: The Testing Of MCB

\begin{tabular}{|l|l|l|}
\hline \multirow{4}{*}{ MCB } & Smartphone status & Note \\
\cline { 2 - 3 } & ON & $\begin{array}{l}\text { all the electrical equipment (KKB, water pump machine, TV, electric } \\
\text { lights and MCB), worked (ON) }\end{array}$ \\
\cline { 2 - 3 } & OFF & $\begin{array}{l}\text { all the electrical equipment (KKB, water pump machine, TV, electric } \\
\text { lights and MCB), unworked (OFF) }\end{array}$ \\
\hline
\end{tabular}

Table 2 : The Testing Of Reservoar If The Input Engine Is Put KKB 2

\begin{tabular}{|l|l|l|}
\hline The level of water & Smartphone status & note \\
\hline $\begin{array}{l}\text { The lowest water level }(15 \mathrm{~cm} \text { from the } \\
\text { bottom of the reservoir) }\end{array}$ & ON & engine water pump is ON \\
\hline $\begin{array}{l}\text { Water lever at the height of the mid }(70 \mathrm{~cm} \\
\text { from the bottom of the reservoir) }\end{array}$ & ON & engine water pump is still ON \\
\hline $\begin{array}{l}\text { The highest water level }(100 \mathrm{~cm} \text { from the } \\
\text { bottom of the reservoir and } 15 \mathrm{~cm} \text { from the } \\
\text { cap reservoir) }\end{array}$ & OFF & engine water pump is OFF \\
\hline
\end{tabular}

\subsection{Discussion}

The testing system for device control and monitoring equipment; electricity that has been done either manually via push-button switch or automatically by using a smartphone has to function perfectly. it can be seen from the test results in Table 1 at which time the lights first lit manually through the switch through the button switch (ON), the smartphone can also be seen on (ON). Otherwise if the button on the smartphone pressed to extinguish the light used was light type push switch ON (switch trigger), then after the switch is pressed (ON) automatically returns to its original position (OFF). at the time of the switch $5 \mathrm{ON}$, for the lamp 5 , it is seen on a smartphone 5-position switch is also in the ON state. The 5 light can be extinguished through a smartphone or via the manual switch. this applies to the lights 2, 3, and 4 at the same table, at which time the KKB1 ON via smartphone, then after tested by using a voltmeter shows the voltage value of 220 volts. This suggests that KKB1 has functioned well. Otherwise if the smartphone is pressed to the OFF position, then the voltage value indicated by KKB1 = 0 Volt. The same thing applies to KKB2 and KKB3. When the ON key is pressed, the smartphone looks light sleeper 1 mounted on KKB1 will light, it gives an idea that KKB1 position in a state function $(\mathrm{ON})$. Conversely when the $\mathrm{OFF}$ button is pressed, then a light sleeper 1 will be extinguished, which means KKB1 position in a state of not functioning (OFF). The same applies to the other electrical equipment. When the OFF button is pressed, it looks a TV mounted on KKB will light, it gives an idea that the position of the CLA has been in a state of function (ON). Conversely when the OFF button is pressed, the TV goes out, that means the position of the CLA in a state of not functioning (OFF). Specifically for tool reservoir in this study can be used in two ways, namely:

The first way: the input cable connected directly to the engine reservoir KKB power market outside the building. in this position the control device automatically placed on the reservoir, will work automatically to control the level of water level in the reservoir, meaning that if the water in the reservoir is at a low level according to the settings of consumers, then the automatic engine water pump will run (function), to fill the reservoir basin and if the reservoir has been filled (at its highest level in the reservoir, the default setting), then the automatic engine water pump will stop and will run (function) automatically if the water tank is empty.

The second ways: the input cable is connected to the machine reservoir KKB one that is in the building market has been created, it can be controlled reservoara (ON - OFF) via smartphones such as the control of the collective labor agreement which has been applied (Table 1). in the event of a short circuit in the electrical installation of a home / building (market building made), then the automatic safety MCB will trip, meaning that the entire device attached to the home / building that Is OFF (extinguished). To enable (ON) back in MCB, can be done manually or automatically, from a short distance, or remotely using a smartphone.

\section{Conclusion}

1) The software-based system monitoring and control arduino mega functioning properly, this is evidenced by the functioning of all the systems of control and monitoring, both the safety devices (MCB), as well as for a variety of electrical equipment for a variety of devices enabled. 
2) Prototype tools based on monitoring and control of arduino mega created to control the electrical equipment (MCB, KKK, KKB, TV, Reservoir and electric lights) has been functioning well, this has been proven in research trials.

3) The application and interface arduino mega-based control system that has been made already functioning well and can control and monitor devices electrical equipment contained in a home or a lot of well-storey building.

\section{Reference}

[1] Brusco, J.M (2010). Using Smartphone Application in Perioperative Practice. AORN Journal Vol.92/5, 503-508

[2] PUIL' 2000. Peraturan Umum Instalasi Listrik. 2000. Jakarta.

[3] Phillippi, J.C and Wyatt, T.H (2011). Smartphone in Nursing Education. CIN: Computers, Informatics, Nursing Vol.29/8, 449-454

[4] R.Thesrumluk, dkk. 2013. Development of Energy Saving Smart Home Prototype Department of Computing, Faculty of Science, Silpakom University, Thailand International Journal of Smart Home Vol. 7, No.1, January, 2013

[5] Sean Young Tjahyadi, Parlinggoman R. H., 2012. Intelligent Building Management System Pada Ac Dan kWh Meter Berbasis Web dan Mobile Android Pada Gedung The Energy. Bina Nusantara University. Jakarta.

[6] Seong Ro Lee, dkk. 2013, Smart Home Control and Monitoring System Using Smart Phone. Proceedings, The $1^{\text {st }}$ International Conference on Convergence and it's Application. ICCA 2013, ASTL Vol. 24, pp. 83-86, 2013.

[7] Widodo Budiharto,S.Si., M.Kom, 2008, Elektronika digital and Mikroprosessor, Andi.

[8] ZERFANI YULIAS, 2011, tutorial singkat bahasa pemrograman arduino,http://. famosastudio.com /2011/06/tutorial/tutorialsingkat-ahasa-pemrograman-arduino/82, diakses 7 Januari 2014. 